ISSN 1991- 8690

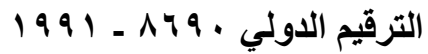

Website: http://jsci.utq.edu.iq

Email: utjsci@utq.edu.iq

\author{
قياس بعض المعادن الثقيلة في مياه آبار منتخبة في مدينة البصرة/العرقق \\ آمال أحمد محمود فياه \\ قسم الكيمياء البحرية_ مركز علوم البحار - جامعة البصرة/العراق
}

الخلاصة

أجريت الدراسة الحالية لقياس معدلات بعض المعادن الثقلة في مياه آبار أختيرت عشوائيا من ثناث مناطق في جنوب محافظة البصرة (الزبير

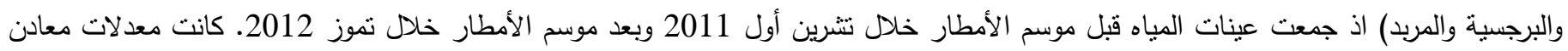

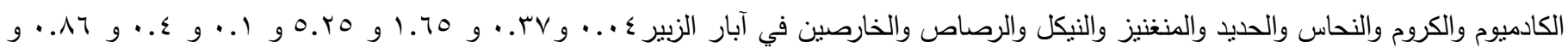

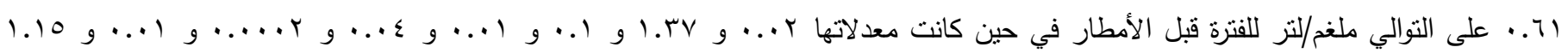

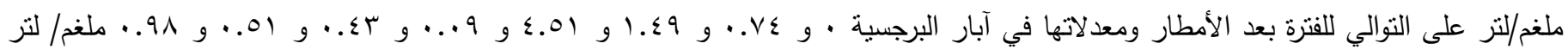

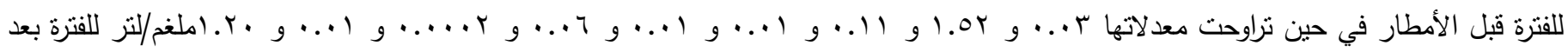

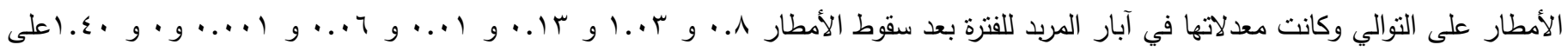
التوالي ملغم/لتر .أظهرت النتائج وجود فروق معنوية العلاقة بين المواقع الا أنها لم تكن معنوية بين آبار الموقع الواحد وقد كان للأمطار تأثير معنوي

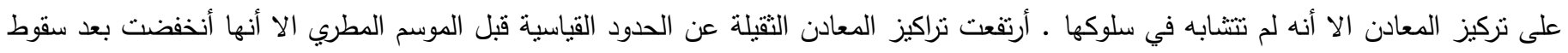

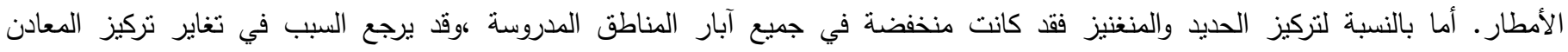

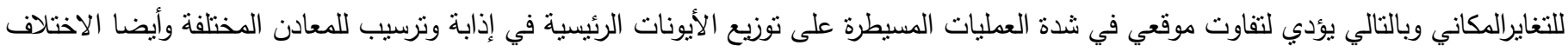

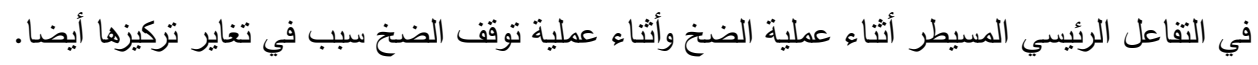
كلمات مفتاحية: معادن ثقيلة ،مياه جوفية ،آبار أرتوازية كمدينة البصرة ،العراق

\title{
Specify some heavy metals in select wellsWater at Basrah,Iraq
} Amal A. Mahmood

\section{$\underline{\text { Abstract }}$}

Department of Marine Chemistry. Marine Science Centre_University of Basrah, Iraq

The present study was undertaken to determine the means of some heavy metals in randomly choosen wells from Basrah: tow regions before raining period during October 2011 (Bergussia and Zubair) and three regions (Bergussia , Zubair and Marbed) after raining period during July 2012. The concentrations of heavy metals $\mathrm{Cd}, \mathrm{Cr}, \mathrm{Cu}, \mathrm{Fe}, \mathrm{Ni}$, $\mathrm{Mn}, \mathrm{Pb}$ and $\mathrm{Zn}$ were $0.004,0.37,1.65,5.25,0.1,0.4,0.86$, and $0.61 \mathrm{mg} / \mathrm{l}$ respectively for the period before rain while $0.02,1.37,0.1,0.01,0.04,0.0002,0.01$ and $1.15 \mathrm{mg} / \mathrm{l}$ respectively for the period after rain in Zubair and $0,0.74$, $1.49,4.51,0.09,0.43,0.51,0.98 \mathrm{mg} / \mathrm{l}$ respectively for the period before rain while $0.03,1.52,0.11,0.01,0.01,0.06$, $0.0002,0.01$ and $1.20 \mathrm{mg} / \mathrm{l}$ respectively in Bergussia, the concentrations recorded in Marbed were 0.8, 1.03, 0.13, 1.01, $0.6,0.001,0$, and $1.40 \mathrm{mg} / \mathrm{l}$ respectively. The result showed significant deferences between the sites, and no segnifincat between wells and the rain was significant effect on concentration of heavy metals. Almost the reason the heterogeneity focus minerals Consequently, differences in the intensity of the on-site processes controlling the distribution of major ions in melting and sedimentation to various metals. As well as the difference in controlling main interaction during pumping operation during the process of pumping cause the differentiation in the concentrations

Key words: Heavy metals, Wells water, underground water, south of Iraq 
Gulfraz et al., 2001). ان محتوى المعادن الثقيلة في التربة والمياه مهم بالنسبة للانسان والنبات ولكن ضمن نسب وقياسات محت محددة

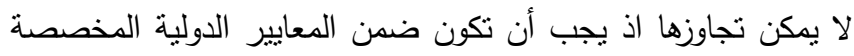

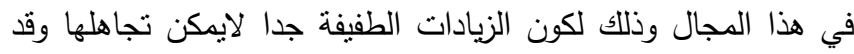

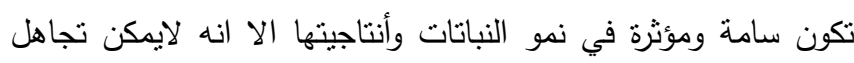

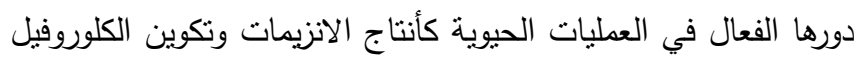

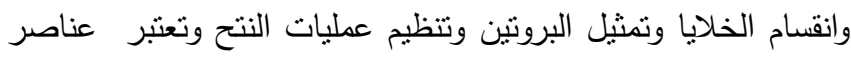

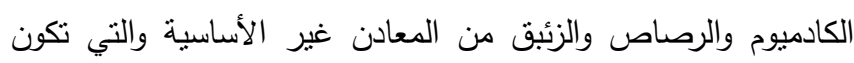

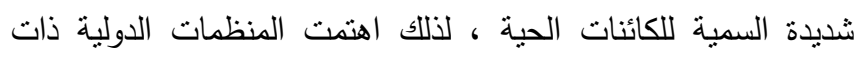

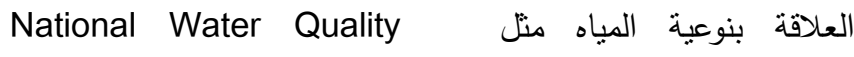
ومنظمة الصحة العالمية (NAWsessment (لونة ) ( Health Canada ) ومنظمة الصحة الكندية WHO,1999) لمعرفة تأثير كل معدن ودوره في الصحة العامة ووضع الحدود العليا المسموح بها في استخدام المياه وحسب المواصفات القياسية ونظام صيانة الانهار من التلوث رقم 25 لسنة 1967. اما مسودة المواصفات ولثات

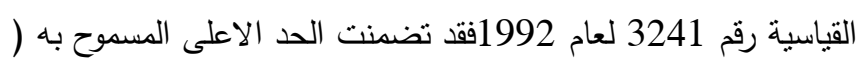
ملغم / لنز) لاستعمال المياه لاغراض الري.وبسبب الزيادة في معدل النمو السكاني وشحة المياه في مناطق الزبير والبرجسية وقلة مياه

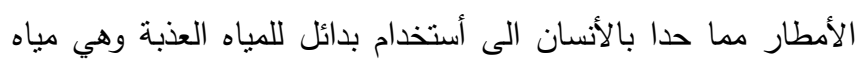

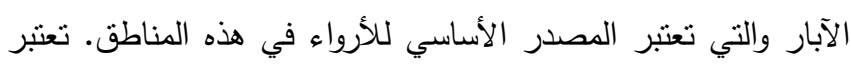

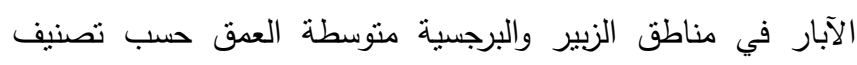

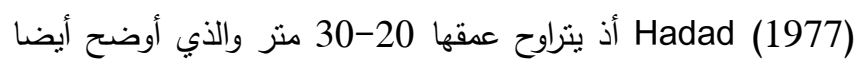
ان طبيعة تكوين تربها والمكونة من أغشية ناضحة تسمح لمياه الأمطار

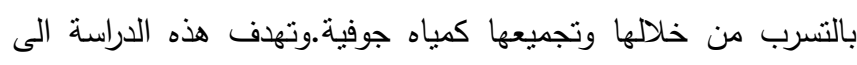

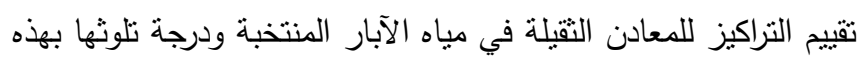

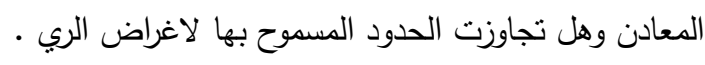

\section{2- مواد العمل وطرائقه}

2-1-2 وصف منطقة الدراسة:

يعد مكمن الدبدبة الفتاتي المصدر الرئيسي للمياه الجوفية المويلحة في

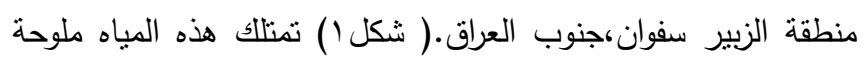

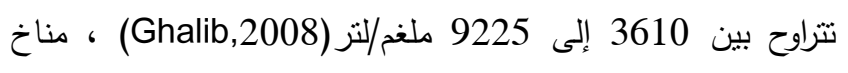

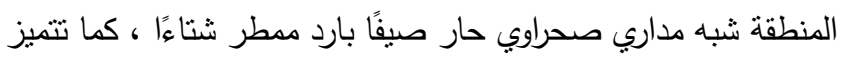

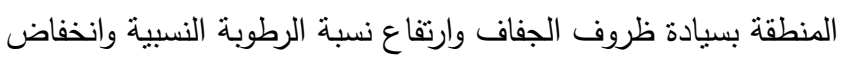

1- المقدمة

ان دراسة تلوث المياه هي من الدراسات المهمة كونها تتعلق بحياة

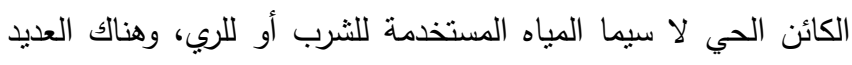

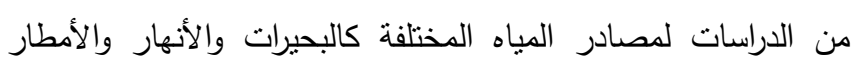
فضلا عن المياه الجوفية ومدى نأثرها بالملوثات التي أرتفعت نراكيزها

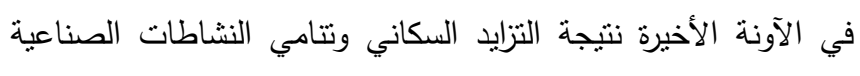

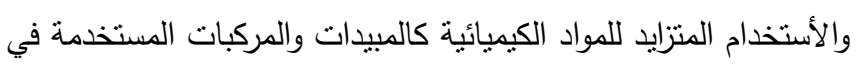
مختلف الصناعات فضلا عن وسائط النقل مما يكون له الأثر الكبير على جودة المياه ونوعيتها، لذا كان وجوب العمل عليها ومنع تلوثنها

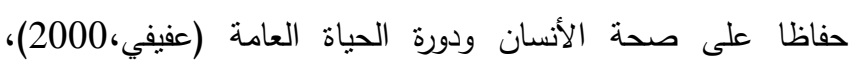

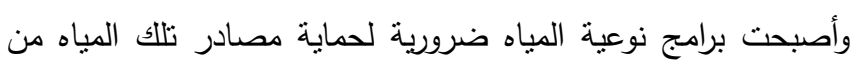
التلوث (Pesce and Wunderlin, 2000) .أن الموارد المائية وما في منياه تمنتك من أهمية محورية للزراعة في العالم وبالأخص على ضوء شحة

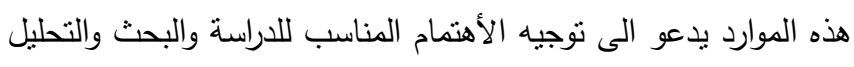

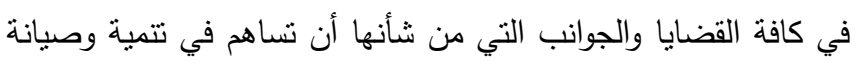
تللك الموارد وتحقيق أقصى مستويات ممكنة من نوعية وكفاءة الأستخدام (الحياني،2003)، ونظرا لتصريف المخلفات الصناعية والمنزلية دون

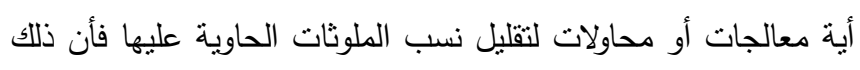

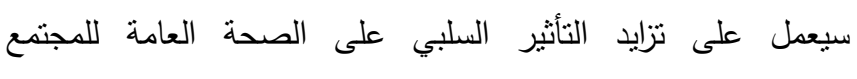
والبيئة.تعد المعادن الثقيلة من الملوثات المؤثرة على المياه الجوفية لئية

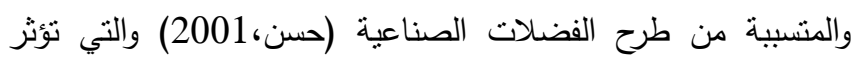

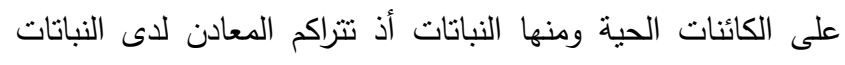

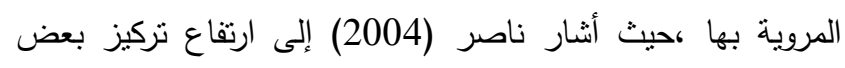
المعادن الثقيلة وزيادة التلوث السمي لدى النباتات المروية بمياه الآبار

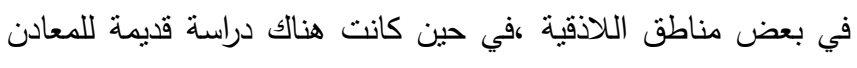

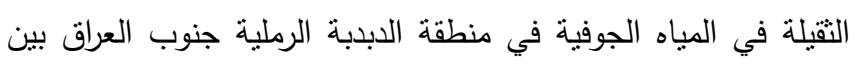

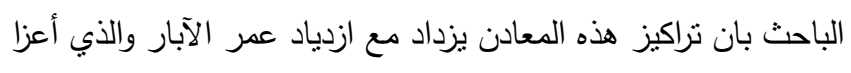
سبب هذه الزيادة إلى تلوث مياه الري العائدة إلى المكمن المائي

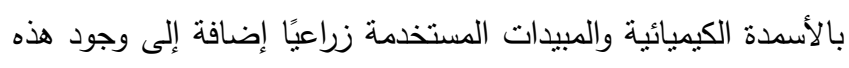

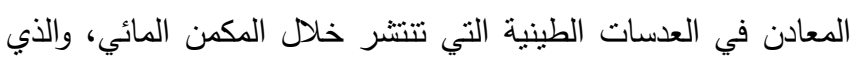

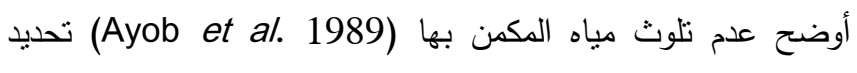
ايونات المعادن النقيلة في النظام يفيد في السيطرة على التلوث خاصنة

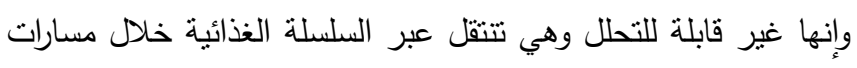
متعددة ولها القابلية على التراكم في أنسجة الكائنات الحية المختلفة 


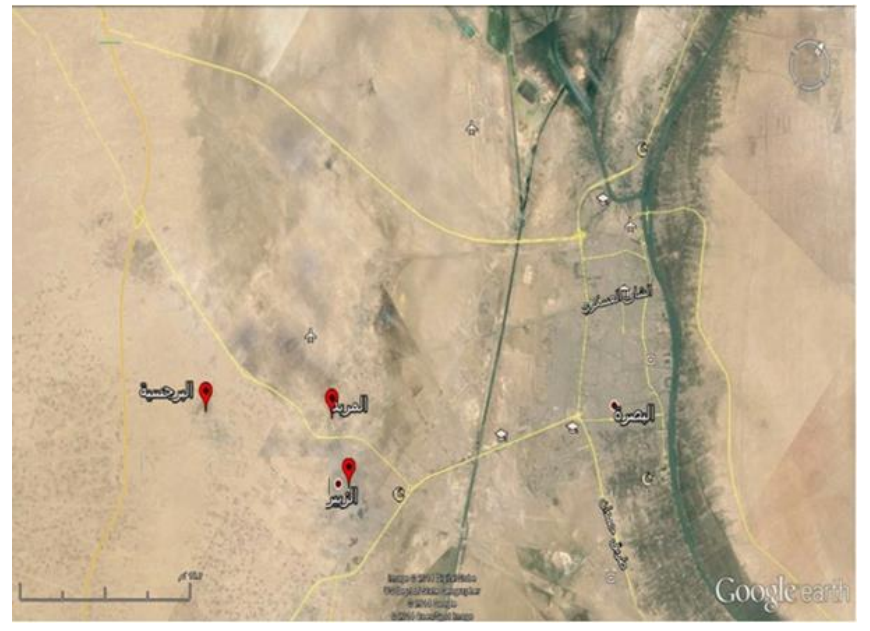

صورة (1) - مبين مواقع الدراس

\section{r- النتائجج}

توضح الأشكال (1-8) معدلات تراكيز المعادن الثقبلة في مياه

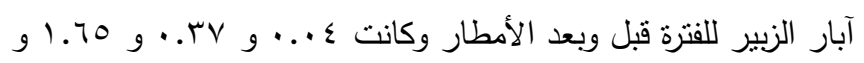

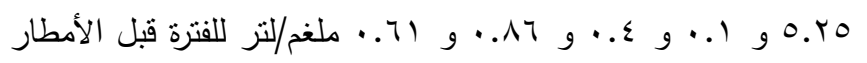

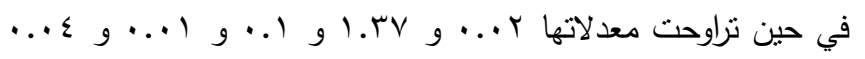

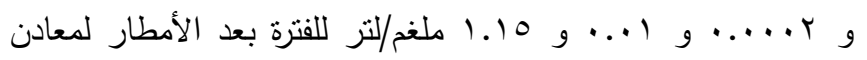

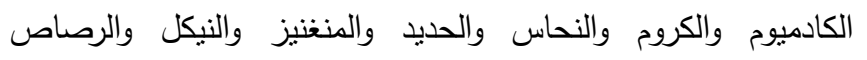

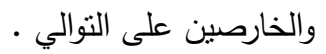

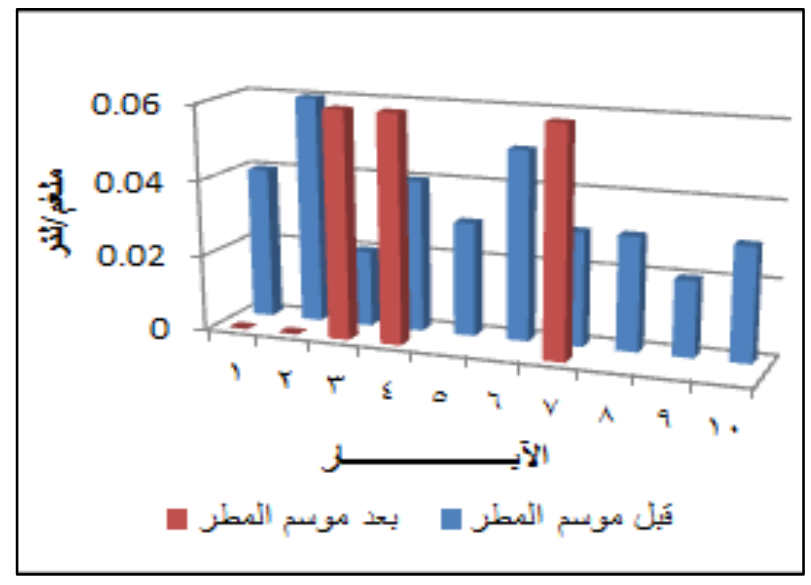

شكل( ) تركيزالكادميوم(ملغم/لتز)في آبار الزبير لموسمي الدراسة
معدلات سرع الرياح عمومًا.مكمن المياه الجوفية المستغل في منطقة

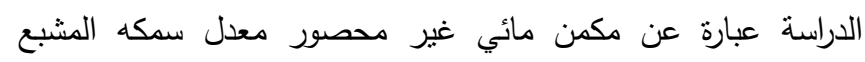

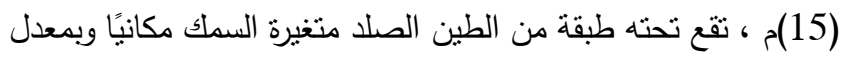

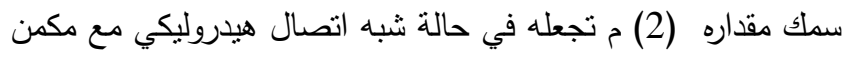

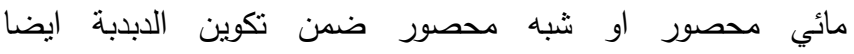

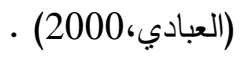

\section{r-r - جمع العينات:}

جَمِعَت عينات الماء من 20 بئر أُختيرَت عشوائِيا في منطقة الزبير والبرجسية كما موضح بالثكل (1) خلال مرحلتين أحدها خلاد

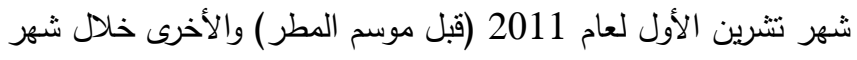

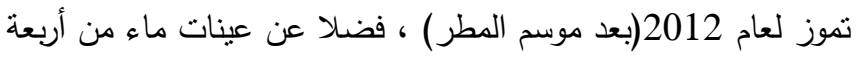

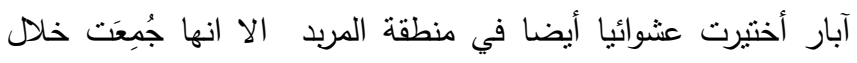

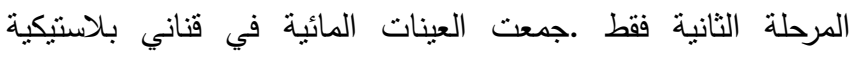
،اضيف لها الكلوروفورم وحامض العيدروكلوريك المركز وحفظت بدرجة

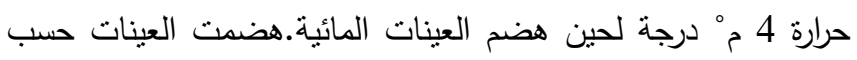
الطريقة الموضحة في (APHA, 1995) وثم قياس المعادن الثقيلة

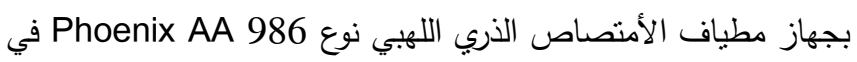
مختبرات كلية الزراعة/جامعة البصرة ـ أعتمد البرنامج الإحصائي في (Statistical Package for Social Science) SPSS التحليل الإحصائي لنتائج هذه الدراسة تحت مستوى معنوية 0.05

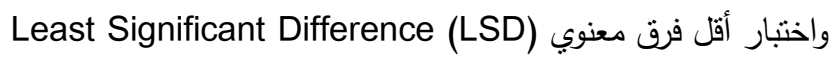

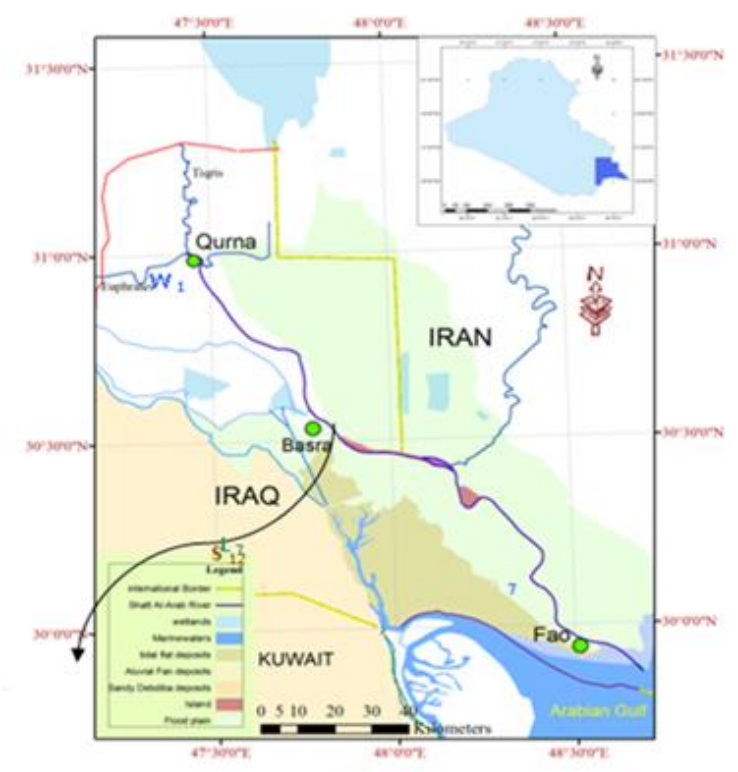




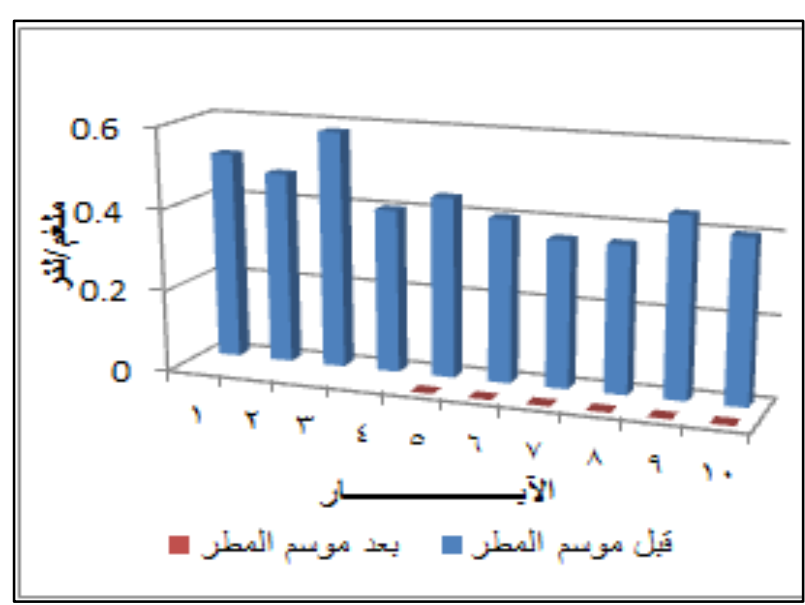

شكل(ه)تركيز النيكل(ملغم/لنر)في آبار الزبير لموسمي الدراسة

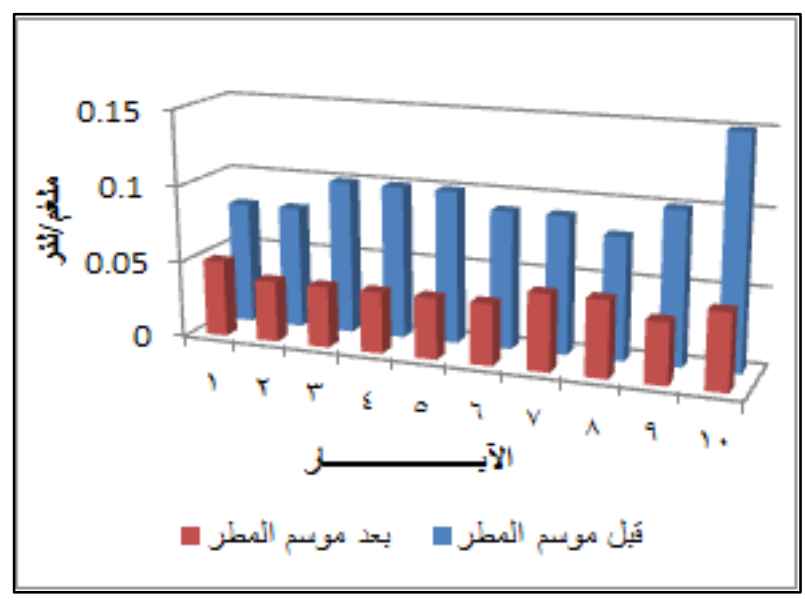

شكل(T)تركيز المنغنيز (ملغم/لتر)في آبار الزبير لموسمي الدراسة

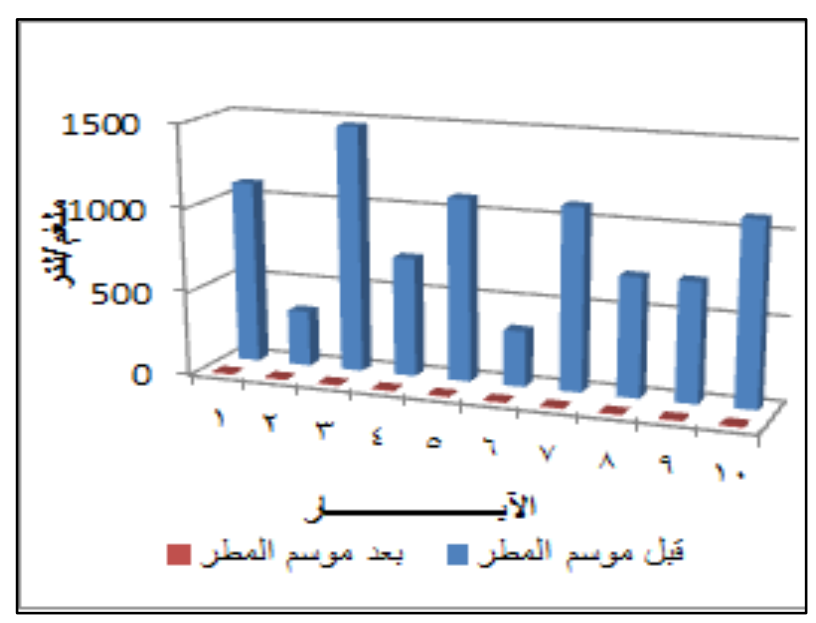

شكل(V)تركيز الرصاص(ملغم/لتر)في آبارالزبير لموسمي الدراسة

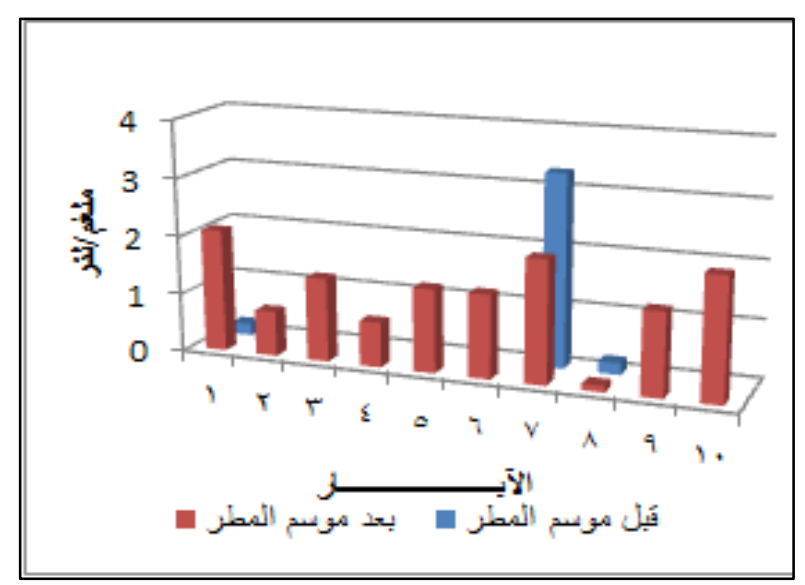

شكل(؟)تركيزالكروم(ملغ//لتر)في آبار الزبير لموسمي الدراسة

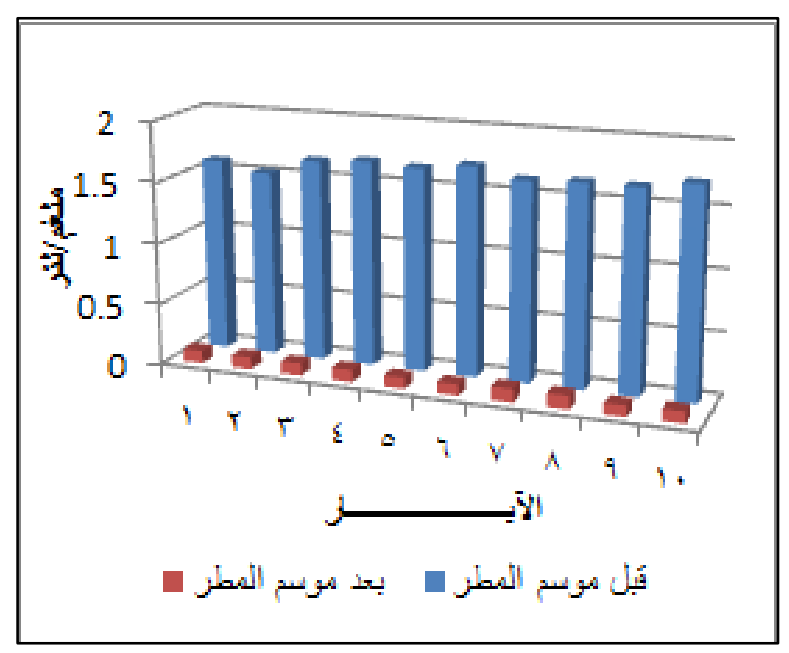

شكل(r)تركيز النحاس(ملغم/لتر)في آبار الزبير لموسمي الدراسة

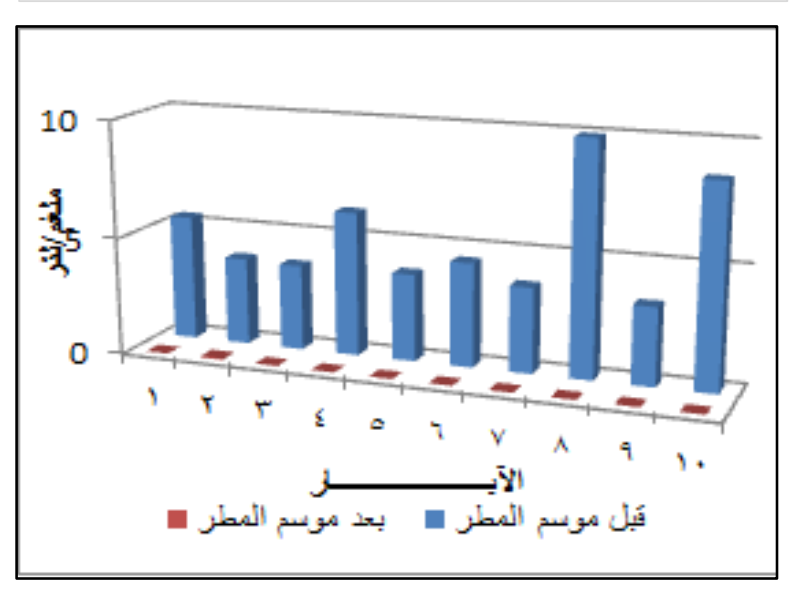

شكل(§)تركيز الحديد(ملغم/لتر)في آبار الزبير لموسمي الدراسة 


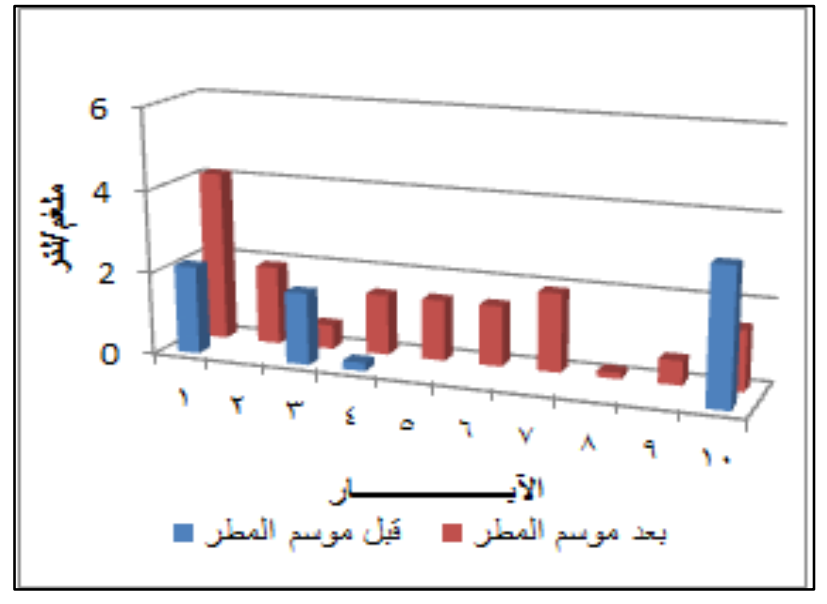

شكل( • ( )تركيزالكروم(ملغم/لتر)في آبار البرجسية لموسمي الدراسة

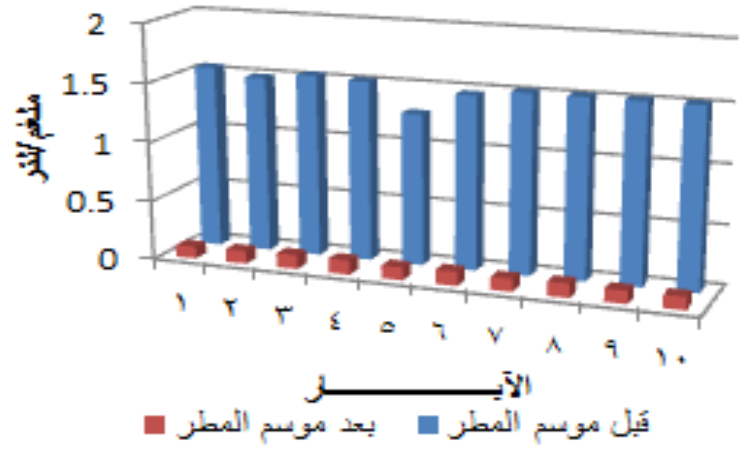

شكل(1 (1) تركيز النحاس(ملغم/لتر)في آبارالبرجسية لموسمي الدراسة

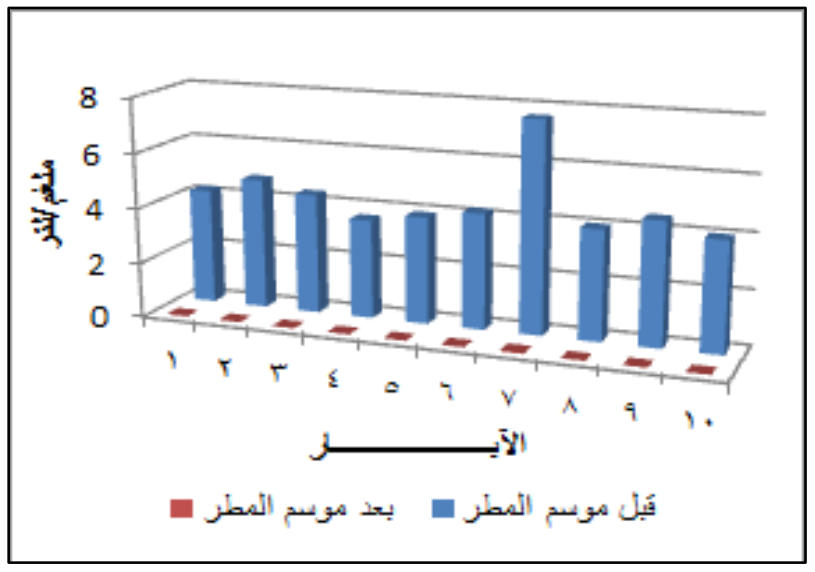

شكل(r ( ) تركيز الحديد(ملغم/لتر)في آبار البرجسية لموسمي الدراسة

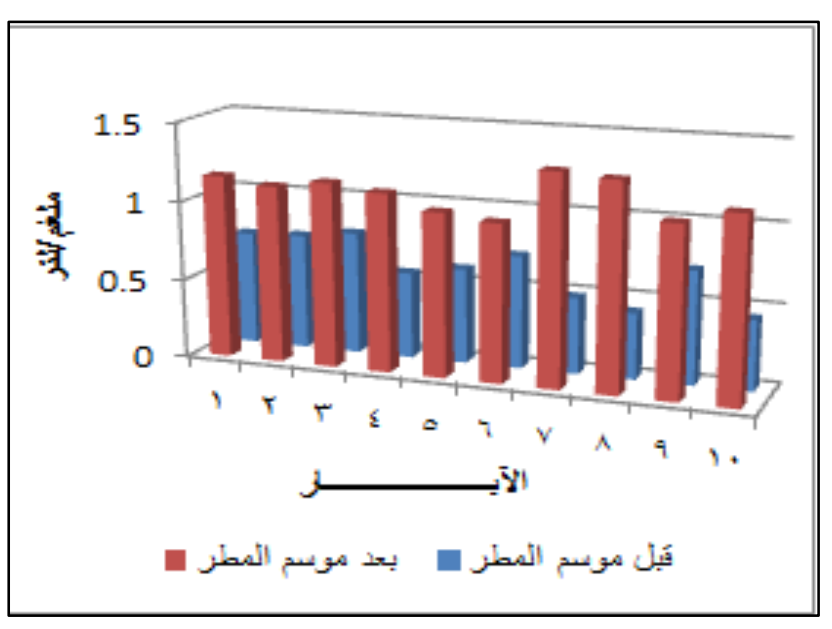

شكل(^)تركيز الخارصين(ملغم/لتز)في آبار الزبير لموسمي الدراسة

وتبين الأشكال (9-10) نركيز المعادن الثقيلة في مياه آبار البرجسية

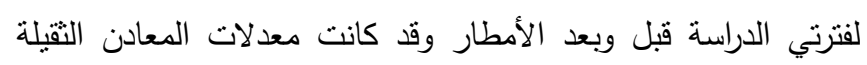
كالتالي . و ع V.. و, و

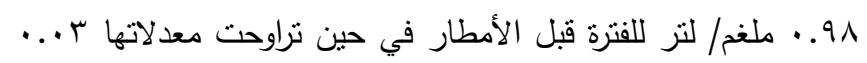
و

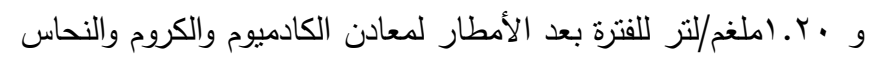

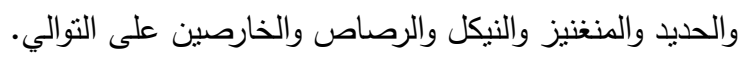

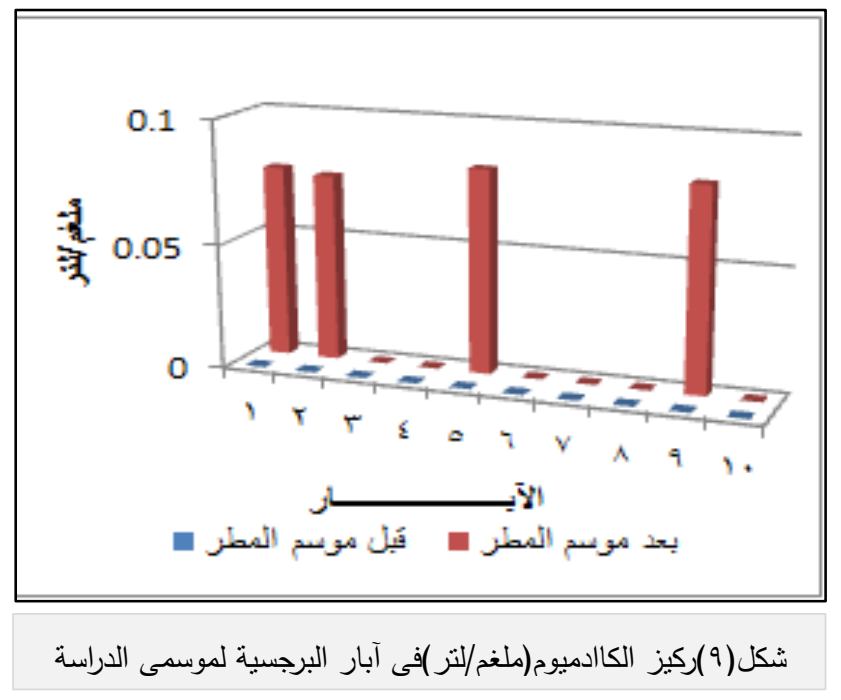




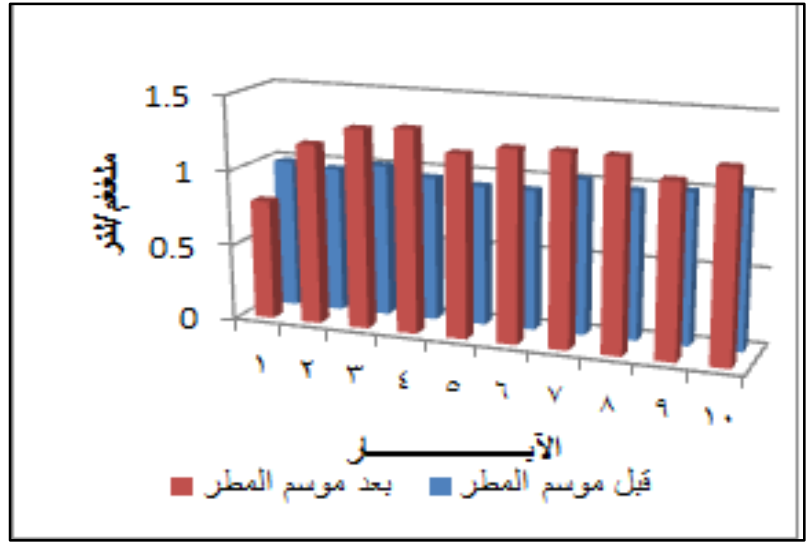

شكل(7 7 ) تركيزالخارصين(ملغم/تنر)في آبارالبرجسيةلموسمي الدراسة

كما بين الثكل (17) معدلات تراكيز المعادن الثقبلة المسجلة في آبار المربد للفترة بعد تساقط الأمطار والذي يلاحظ فيه تفاوت التراكيز

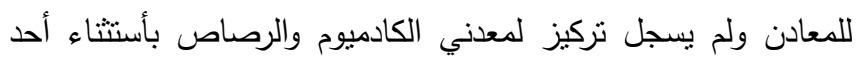
الآبار اذ سجل تركيز الكادميوم فيه ^.. مايكغم/لتز كما يلاحظ نراكيز

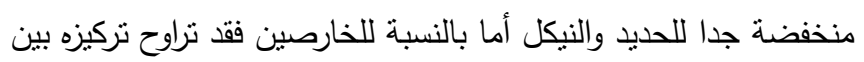

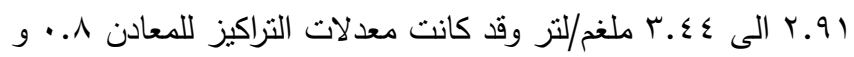

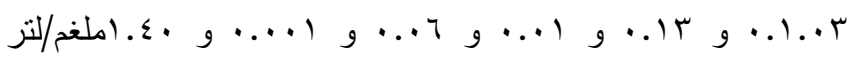

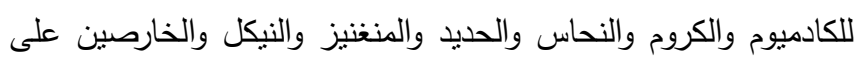

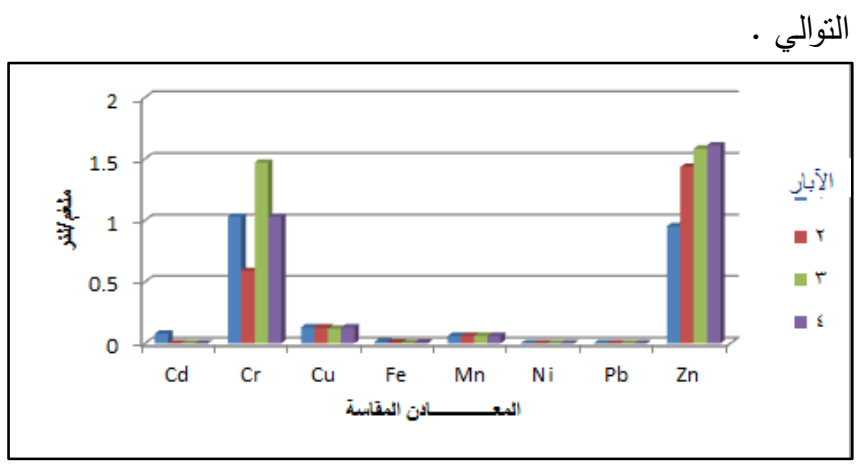

شكل(V) ايبين تراكيز المعادن الثقيلة(ملغم/لنز)في آبار المردد

تبين النتائج في جدول (1) المعدلات والأنحراف القياسي لتأثير أختلاف الموقع على تركيز المعادن الثقيلة أذ يلاحظ وجود فروق

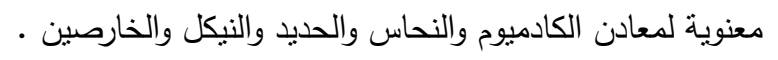

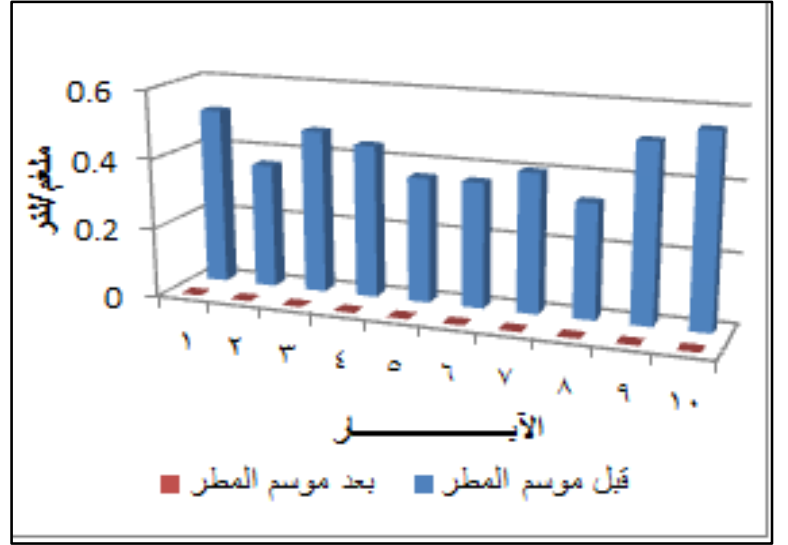

شكل(ب ا )تركيزالنيكل(ملغم/لتر)في آبار البرجسية لموسمي الدراسة

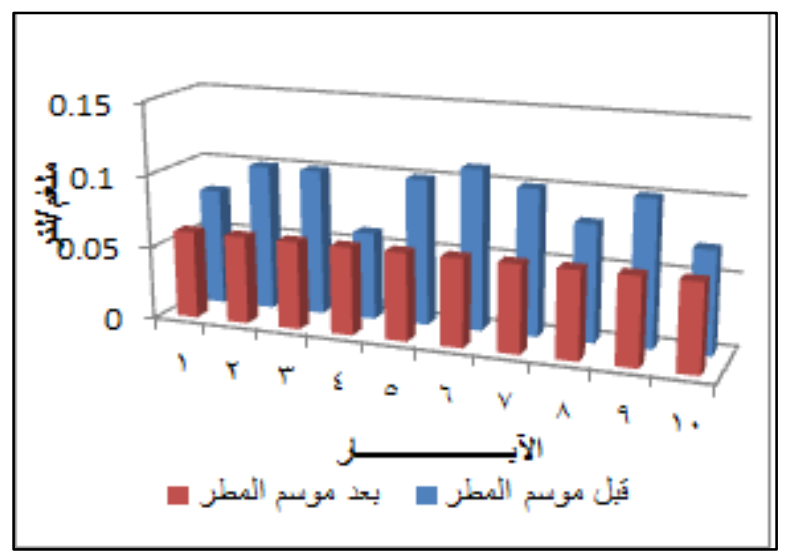

شكل(ع ( )تركيزالمنغنيز (ملغ/لتزر)في آبارالبرجسية لموسمي الدراسة

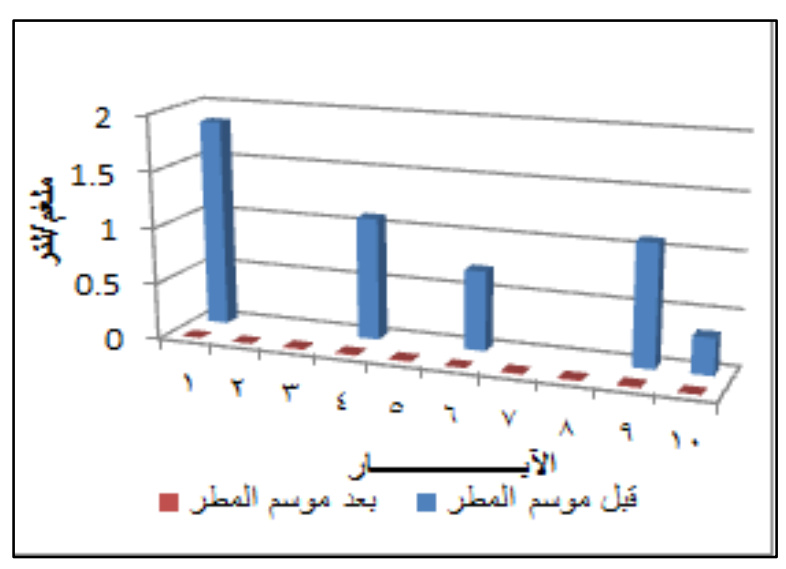

شكل(0 1 )تركيزالرصاص(ملغ/لتر )في آبارالبرجسيةلموسمي الدراسة 
جدول(r) ييين المتوسط والأنحر اف القياسي للمعادن الثقيلة للآبار المنتخبة في الدراسة الحالية

\begin{tabular}{|c|c|c|c|c|c|c|c|c|c|}
\hline الايخر & & $\mathrm{Cd}$ & $\mathrm{Cr}_{\mathbf{r}}$ & $\mathrm{Cu}$ & $\mathrm{Fe}$ & Mn & $\mathrm{Ni}$ & $\mathrm{Pb}$ & $\mathbf{Z n}$ \\
\hline \multirow[t]{2}{*}{$T$} & المتوسيط & 0.049 & 1.918 & 0.694 & 1.914 & 0.066 & 0.255 & 0.738 & 0.923 \\
\hline & الأتحر اقت القيَاسي & 0.038 & 1.472 & 0.800 & 2.643 & 0.013 & 0.294 & 0.901 & 0.173 \\
\hline \multirow[t]{2}{*}{$r$} & المتوسط & 0.068 & 1.090 & 0.670 & 1.710 & 0.068 & 0.208 & 0.113 & 1.089 \\
\hline & الأتحر اقت القياسي & 0.011 & 0.716 & 0.762 & 2.342 & 0.023 & 0.244 & 0.188 & 0.262 \\
\hline \multirow[t]{2}{*}{$T$} & المتوسيط & 0.020 & 1.310 & 0.706 & 1.604 & 0.072 & 0.263 & 0.497 & 1.171 \\
\hline & الآتحر اقت الإياسي & 0.028 & 0.501 & 0.813 & 2.206 & 0.027 & 0.306 & 0.843 & 0.307 \\
\hline \multirow[t]{2}{*}{$\leqslant$} & المتوسط & 0.025 & 0.868 & 0.710 & 1.953 & 0.064 & 0.210 & 0.455 & 1.116 \\
\hline & الأتحر اقت القياسي & 0.030 & 0.531 & 0.814 & 2.814 & 0.022 & 0.243 & 0.537 & 0.402 \\
\hline \multirow[t]{2}{*}{0} & المتوسيط & 0.056 & 1.450 & 0.785 & 1.907 & 0.075 & 0.200 & 0.370 & 0.942 \\
\hline & الآتحر اقت القياسي & 0.037 & 0.028 & 0.806 & 2.199 & 0.030 & 0.233 & 0.624 & 0.255 \\
\hline \multirow[t]{2}{*}{7} & المتوسطط & 0.025 & 1.450 & 0.848 & 2.162 & 0.075 & 0.190 & 0.263 & 0.975 \\
\hline & الآتحر اقت القياسي & 0.035 & 0.028 & 0.863 & 2.493 & 0.031 & 0.220 & 0.335 & 0.226 \\
\hline \multirow[t]{2}{*}{$\mathrm{v}$} & المتوسيط & 0.030 & 2.437 & 0.843 & 2.832 & 0.075 & 0.254 & 0.370 & 1.026 \\
\hline & الأتحر اقت القياسي & 0.030 & 0.754 & 0.847 & 3.633 & 0.024 & 0.220 & 0.624 & 0.386 \\
\hline \multirow[t]{2}{*}{$\Lambda$} & المتوبسط & 0.015 & 0.153 & 0.850 & 3.484 & 0.068 & 0.173 & 0.243 & 0.991 \\
\hline & الأتحراق القياسي & 0.021 & 0.045 & 0.850 & 4.692 & 0.015 & 0.199 & 0.404 & 0.408 \\
\hline \multirow[t]{2}{*}{4} & المتوبط & 0.051 & 1.010 & 0.843 & 1.955 & 0.075 & 0.238 & 0.455 & 0.982 \\
\hline & الآتحر اقت القياسبي & 0.044 & 0.594 & 0.859 & 2.301 & 0.030 & 0.276 & 0.537 & 0.187 \\
\hline \multirow[t]{2}{*}{1.} & المتوسيط & 0.010 & 2.290 & 0.860 & 3.149 & 0.083 & 0.238 & 0.358 & 0.971 \\
\hline & الآتحر اقت القياسي & 0.017 & 0.930 & 0.875 & 4.088 & 0.046 & 0.281 & 0.512 & 0.362 \\
\hline \multirow[t]{3}{*}{ الكلاي } & المتوسط & 0.033 & 1.420 & 0.773 & 2.224 & 0.072 & 0.222 & 0.396 & 1.024 \\
\hline & الأتحر اقت القياسي & 0.031 & 0.964 & 0.738 & 2.736 & 0.024 & 0.225 & 0.531 & 0.285 \\
\hline & LSD & 0.048 & 1.423 & 0.091 & 1.774 & N.S & 0.073 & 0.460 & 0.229 \\
\hline
\end{tabular}

\section{4- المناقشتة}

أظهرت نتائج التحليل الأحصائي تباين لبعض المعادن التقيلة

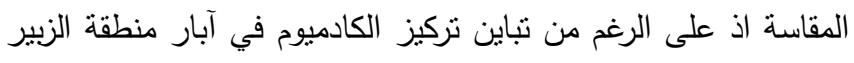

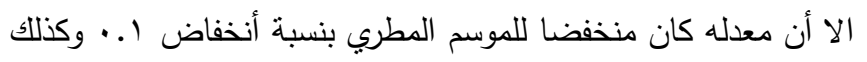

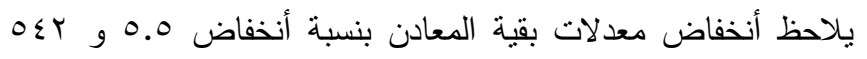

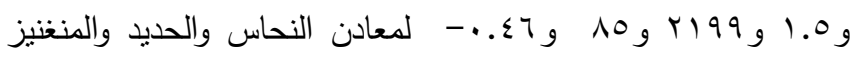

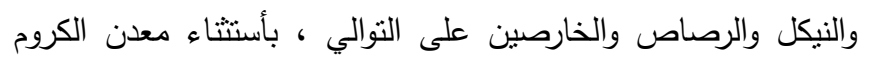
الذي أرتفع معدل نركيزه للموسم المطري في آبار المنطقة نفسها.وقد بادي

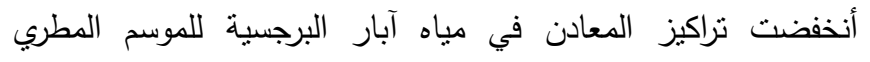

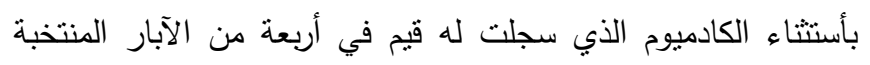

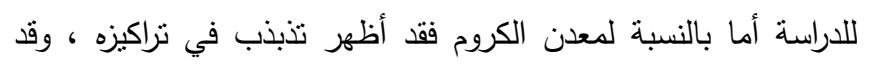

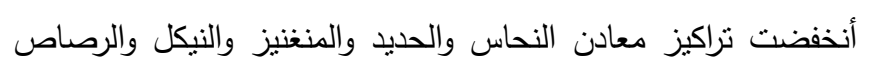

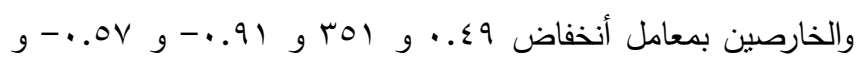

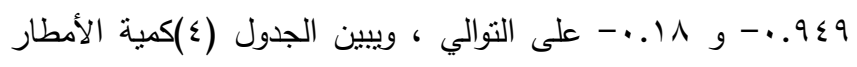

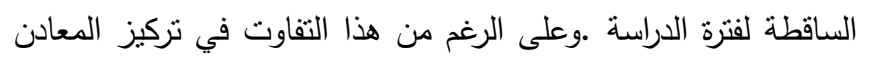

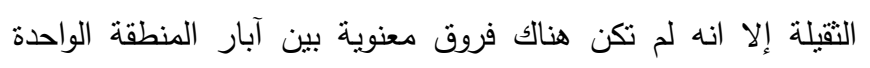

جدول( (1) يبين المتوسط والأنحراف القياسي للمعادن الثقيلة للمواقع الثلاثة

\begin{tabular}{|c|c|c|c|c|c|c|c|c|c|}
\hline المواقع & & $\mathbf{C d}$ & $\overline{\mathrm{Cr}}$ & $\mathbf{C u}$ & $\mathbf{F e}$ & Mn & $\mathbf{N i}$ & $\mathbf{P b}$ & $\mathbf{Z n}$ \\
\hline \multirow[t]{2}{*}{ الزبيير } & المعدل & 0.023 & 1.610 & 0.803 & 2.261 & 0.075 & 0.215 & 0.342 & 0.880 \\
\hline & الأحرات القِياسي & 0.037 & 1.106 & 0.710 & 2.442 & 0.019 & 0.226 & 0.577 & 0.297 \\
\hline \multirow[t]{2}{*}{ البرجسيً } & المعدل & 0.041 & 1.336 & 0.872 & 2.631 & 0.071 & 0.291 & 0.436 & 1.092 \\
\hline & الأحرافت القياسيب & 0.016 & 0.930 & 0.794 & 3.125 & 0.031 & 0.220 & 0.505 & 0.159 \\
\hline \multirow[t]{2}{*}{ المريد } & المعل & 0.080 & 1.030 & 0.128 & 0.008 & 0.060 & 0.001 & & 1.396 \\
\hline & الأحرراف القيّاسي & & 0.359 & 0.005 & 0.005 & 0.000 & 0.001 & & 0.305 \\
\hline \multirow[t]{3}{*}{ الكلي } & المعل & 0.033 & 1.420 & 0.773 & 2.224 & 0.072 & 0.222 & 0.396 & 1.024 \\
\hline & الألحرافت القياسي & 0.031 & 0.964 & 0.738 & 2.736 & 0.024 & 0.225 & 0.531 & 0.285 \\
\hline & LSD & 0.035 & N.S & 0.069 & 2.253 & N.S & 0.076 & N.S & 0.212 \\
\hline
\end{tabular}

وبينت نتائج التحليل الأحصائي عدم وجود فروق معنوية لمعدن الكروم للفتزة قبل وبعد تساقط الأمطار كما موضح في الجدول (r). جدول(r) ييين المعدل والأنحراف القياسي للمعادن النقيلة لموسمي الدراسة

\begin{tabular}{|c|c|c|c|c|c|c|c|c|c|}
\hline الموسم & & $\mathbf{C d}$ & $\mathrm{Cr}$ & $\mathbf{C u}$ & $\mathrm{Fe}$ & Mn & $\mathbf{N i}$ & $\mathbf{P b}$ & $\mathbf{Z n}$ \\
\hline \multirow[t]{2}{*}{ مُبْل المطر } & المتوسط & 0.025 & 1.584 & 1.569 & 4.884 & 0.094 & 0.433 & 0.913 & 0.798 \\
\hline & الأحرافت القيّاسي & 0.020 & 1.413 & 0.102 & 1.813 & $\mid 0.018$ & 0.072 & 0.428 & 0211 \\
\hline \multirow[t]{2}{*}{ بعث المطر } & المتّوسط & 0.041 & 1.373 & 0.110 & 0.008 & 0.053 & 0.000 & 0.008 & $\mid 1.212$ \\
\hline & الأكرافت القِياسي & 0038 & 0825 & 0012 & 0.011 & 0.009 & 0.000 & 0.004 & 184 \\
\hline \multirow[t]{2}{*}{ الكلي } & المتّوسط & 0.033 & 1.420 & 0.773 & 2.224 & 0.072 & 0.222 & 0.396 & 1.024 \\
\hline & الأكرافت القِياسي & 0.031 & 0.964 & 0.738 & 2.736 & 0.024 & 0.225 & 0.531 & 0285 \\
\hline & LSD & 0.031 & N.S & 1.463 & 4.877 & 0.041 & 0.427 & 0.920 & 0.377 \\
\hline
\end{tabular}

أما بالنسبة للآبار فقد بينت نتائج التحليل الأحصائي وجود فروقات

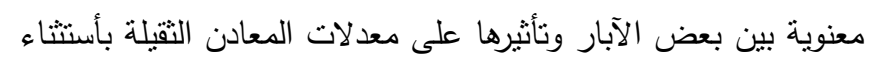

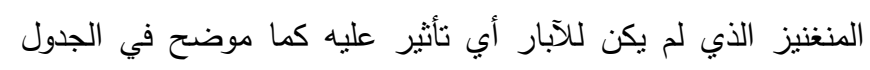


خلال المواسم الزراعية(محسن وآخرون ،2007). كما بين المنصوري(2000)أيضا ان نوع المياه الجوفية في بعض آبار المنطقة

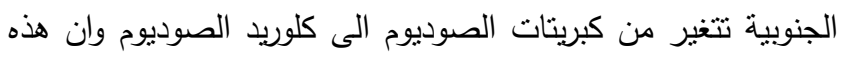

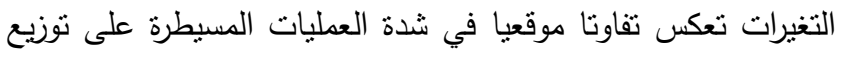

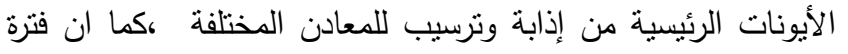

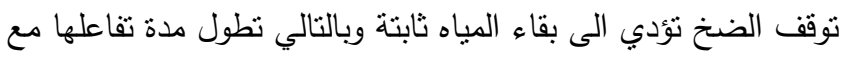

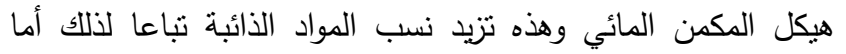
باستمرار الضخ فهنالك فرصة للتعويض عن المياه المسحوبة بمياه اقل ملوحة بشكل مستمر وقد يؤثر هذا على تركيز المعادن .كما أن المياه البحرية قد يكون لها دور في زيادة تركيز المعادن وهذا ما أكده

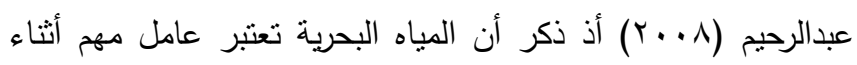

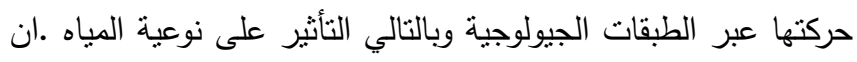

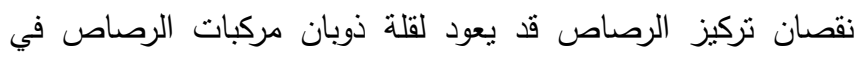
المياه الجوفية وهذا ما أكده (1986) Faure وآخرون ، كما أكد زيدان وآخرون (2007) زيادة الكروم في المياه الجوفية لآبار في القائم وحديثة وهيت.قورنت تراكيز المعادن في الدراسة الحالية مع التراكيز المسموح لها لمياه الأنهار وللمياه المستخدمة للري وكذللك مع التزاكيز

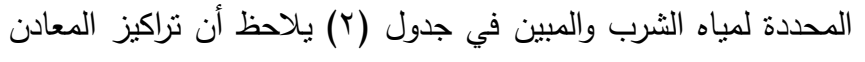

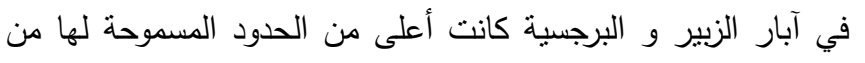
حيث أستعمالها للري أو كمياه شرب للفترة قبل المطر الانيل أن أن معظمها كانت أقل بعد نساقط الأمطار أما بالنسبة لآبار منطقة المربد فيلاحظ لإنط

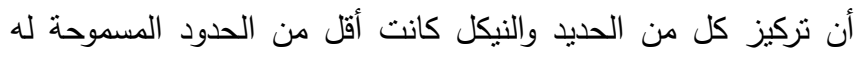

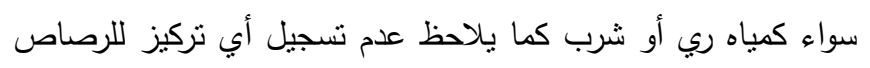

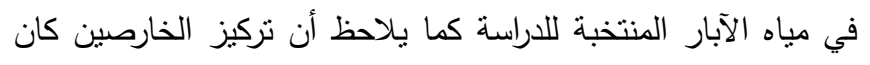

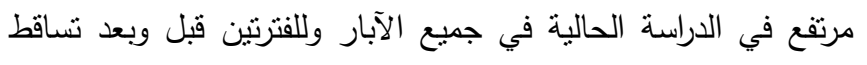
الأمطار وقد يعود سبب التفاوت في تركيز المعادن لكون الأراضي الإني

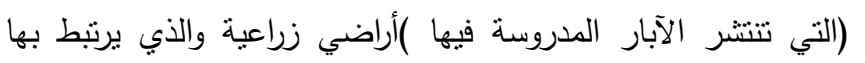

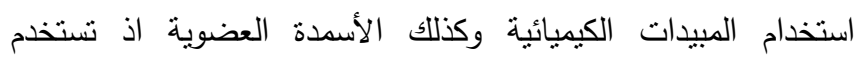

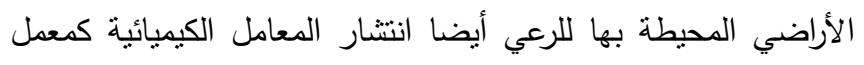
البتروكيمياويات ومعمل غاز الجنوب ومعمل الأسمدة .
وتتقق النتائج مع ماذكره علكم وكاظم (2011) إلا ان الأمطار كان لها

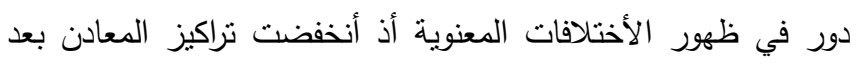
سقوط الأمطار وذللك بسبب زيادة الخزين المائي وبالتالي فأن عامل

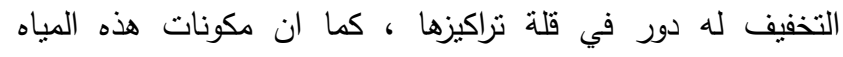

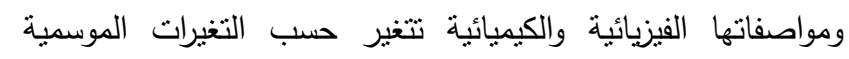
وأعماق الآبار والتكوينات الجيولوجية وظروف سحب المياه وغيره (مؤيد وآخرون ، 2010). (2010. جدول (乏) يبين كمية الأمطار المتساقطة(ملمنر) للفترة من شهر

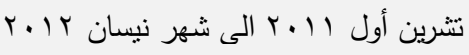

\begin{tabular}{|c|c|c|c|c|c|c|}
\hline الآيام & تشترين أول & تُشرين ثُاني & كانون أول & كانون ثُاني & شباط & نيسان \\
\hline 1 & & & & & 9.6 & 0.2 \\
\hline 5 & & 0.3 & & & & \\
\hline 8 & & & & & 3.3 & \\
\hline 9 & & & & & 0.2 & \\
\hline 10 & & & & قليل جدا & & \\
\hline 11 & & & & 2.0 & & \\
\hline 12 & & قليل جدا & & & & 4.2 \\
\hline 15 & & 1.6 & & & قليل جدا & \\
\hline 16 & & 1.5 & & & & 0.2 \\
\hline 19 & & 28.5 & & & & \\
\hline 24 & & & & & 0.5 & \\
\hline 25 & & & & & 0.8 & \\
\hline 30 & & & & 1.0 & & 2.0 \\
\hline 31 & 1.1 & & 1. & 9.5 & & \\
\hline
\end{tabular}

وقد أوضح المنصوري (2000) ان هناك تغايرا مكانيا كبيرا حيث تتبدل

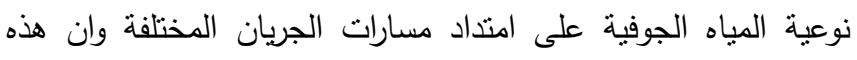

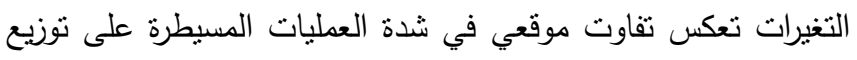
الأيونات الرئيسية في إذابة وترسيب للمعادن المختلفة ، كما في أوضح

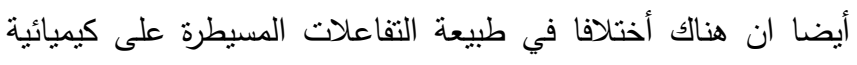

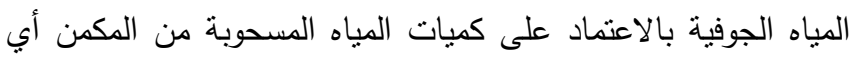

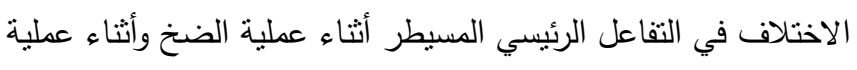
توقف الضخ.وكذلك بين التمر (2005) ان الظروف المناخية لها دور

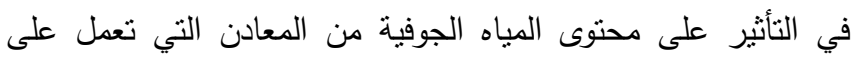

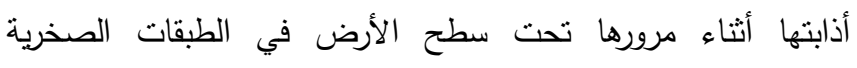
المختلفة.قد يكون لنضوب المكمن المائي الأثر في أرتفاع تركيز

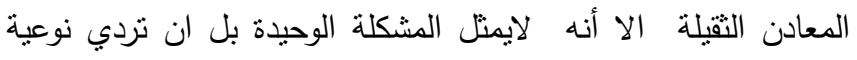

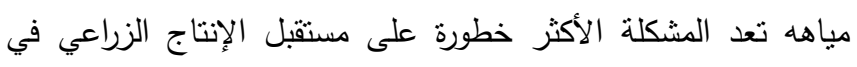

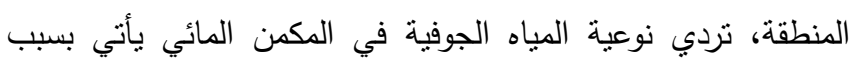

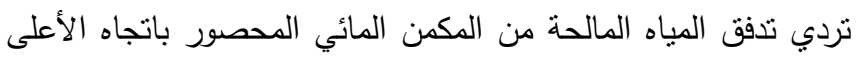

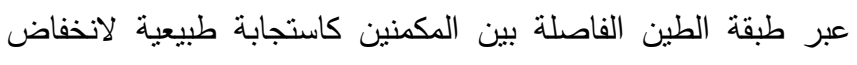

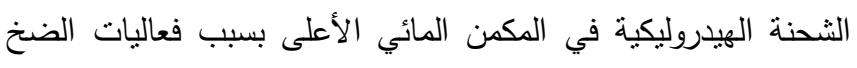


حسن، فاطمة عبد العزيز(2001). أستخدام مياه المجاري المعالجة في اقامة غابات صناعية .المنظمة العربية للتتمية الزراعية. المجلة

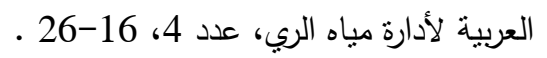

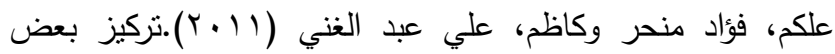

العناصر النزرة في المياه الجوفية لأربعة آبار في مدينة

الخضر/محافظة المثنى/العراق، مجلة القادسية للعلوم الصرفة،

$$
.11-1 ،(r) 17
$$

محسن؛ علاء و داود سلمان بناي و وسام رزاق مطشر و قاسم

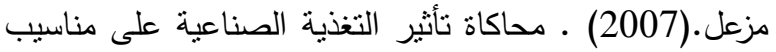
المياه الجوفية لمكمن الدبدبة الرملي في منطقة سفوان، جنوب

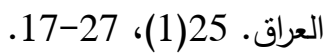

عفيفي، فتحي عبد العزيز (2000). دينامكية السموم والملوثات البيئية

.دار الكتب الحديثة،مصر . طبعة 1، 254 صفحة .

ناصر , أميمة محمد(ع . ․). تأثير التلوث الجرثومي والكيميائي لمياه بعض المسطحات المائية في محافظة اللاذقية على النباتات المروية بهذه الميا هـ ـ رسالة ماجستير -بيئة مائية , كلية العلوم ، جامعة تثرين ,اللاذقية- سوريا 177, صفحة. وزارة التخطيط ( 1992 ) ـ مسودة المواصفات القياسية رقم 3241 . الجهاز المركزي للنقييس والسيطرة النوعية ـ بغداد . وزارة الصحة ( 1998 ) ـ التشربعات البيئية ـ مركز حماية وتحسين لغنين

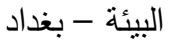

محمد ؛مؤيد حسن ،علاء عادل مزهر و عماركاظم مكي البعاج. (2010). تقدير النترات والنتريت والكلورايد في المياه الجوفية لبعض الآبار في محافظة البصرة / جنوب العراق ـ مجلة أبحاث

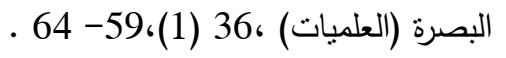

APHA (American Public Helth Association) (1995). Standard methods for examination of water and wastewater, Washington, DC 20036, 1193P.

Ayob, M. S., Al-Ani, S. A. and Al-Talabani, N. (1989). The variation of $\mathrm{Fe}, \mathrm{Mn}, \mathrm{Ca}$ and

$\mathrm{Zn}$ concentrations in the groundwater of the Dibdibba sand aquifer, S. Iraq,

Proc. 5th Sci. Conf./ Src. Iraq, Vol. 1, Part 3, pp: 3340.

Faure, G.(1986). Principles of isotope geology, 2nd

\begin{tabular}{|c|c|c|c|c|c|}
\hline $\begin{array}{l}\text { FEPA } \\
\text { (FEPA, } \\
2003 \text { ) }\end{array}$ & $\begin{array}{c}\text { Usphs } \\
1991 \\
\text { Ppm }\end{array}$ & $\begin{array}{c}\text { USEPA } \\
\text { (USEPA, 1987) }\end{array}$ & 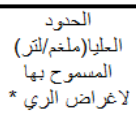 & 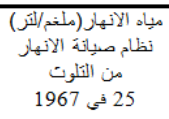 & العنصر \\
\hline 0.008 & 0.01 & 0.008 & 0.01 & 0.005 & أكادميوم \\
\hline \multirow[t]{2}{*}{0.10} & 1.3 & 0.10 & 0.2 & 0.05 & النحاس \\
\hline & 0.1 & & 0.1 & 1 & الكروم \\
\hline \multirow[t]{3}{*}{0.10} & 0.3 & 0.10 & 5 & $0.5-1$ & الحديد \\
\hline & 0.05 & & 0.2 & $0.5-1$ & المنغنيز \\
\hline & & & 0.2 & 0.1 & النيكل \\
\hline 0.0058 & & 0.0058 & 0.1 & 0.03 & الرصاص \\
\hline 0.0766 & 5 & 0.0766 & 2 & $0.5-1$ & لخارصين \\
\hline
\end{tabular}
ed., John Wiley \& Sons, New York. 262 p.

Federal Environmental Protection Agency (FEPA) (2003), Guidelines and Standards for
جدول (0) يبين الحدود المسموح بها لاستخدامات المياه

* وزارة التخطيط ، الجهاز المركزي للتقيس والسيطرة النوعية . حسب المواصفات القياسية رقم 3241 لعام 1992

\section{References} 0- المصادر

التمر، مصعب عبد الجبار. (2005). إيجاد معامل نوعية الماء لمجموعة من الآبار شمال غرب مدينة الموصل. مجلة علوم الرافدين، المجلد 16 ، العدد 2 خاص بعلوم الأرض ،27 40 - 40

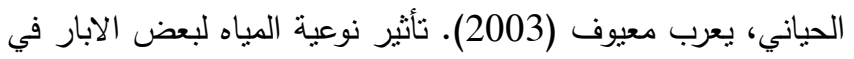
خواص التربة وانتاج الذرة البيضاء، رسالة ماجستير. كلية الزراعة - جامعة الانبار ،العراق ،185 صفحة.

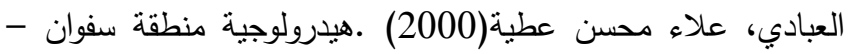

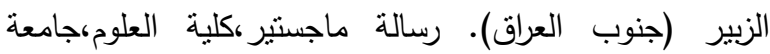
البصرة، العراق،84 صفحة.

رحيم، نجم عبداله (^ . . ب). دراسة جغرافية لنوعية المياه الجوفية في

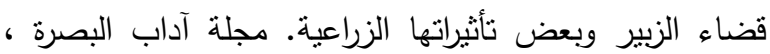

$$
\text { عدد (\&V) • }
$$

زيدانهتحسين علي و رافع قدوري الكبيسي و فراس فاضل علي(2007). تأثير المياه الجوفية والعيون الكبريتية في نوعية مياه نهر الفرات من الحدود السورية إلى منطقة هيت في محافظة الأنبار ـ مجلة جامعة الأنبار للعلوم الصرفة،المجلد الأول. 9 صفحة المنصوري، حسين بدر غالب (2000). هيدروجيوكيمبائية وتأثير عمليات الضخ على نوعية المياه الجوفية لمكمن الدبدبة في منطقة سفوان - الزبير (جنوب العراق). رسالة ماجستير -كلية العلوم جامعة البصرة. 150صفحة. 
Environmental Pollution Control in Nigeria, Nigeria

Ghalib, H. B. (2008). Simulation Study of the effect of artificial recharge on the water quality of shallow Dibdibba Clastic Aquifer in Zubair-Safwan area, south of Iraq. Journal Basrah Researches(Sciences),34(4).11p.

Gulfraz, M. ; Ahmad, T. and Afzal, H. (2001). Concentration of trace metals in the fish and relevant water from Rawal and Mangla lakes. Online Journal of Biological Science, 1(5): 414416.

Hadad, R.H.(1977). " Hydrology of the Safwan Area, South Iraq " Ph.D. Thesis ,University of London $.233 \mathrm{P}$

Pesce, S. F. and Wunderlin, D. A. (2000). Use of Water Quality Indices to verify the impact of Coardoba city (Argentina) on Suquoaa River. Water Research., 34(11): 2915-2926.

USEPA, 1991. Safe Drinking Water Act, 1991 Amendments, EPA 570/9-86-002. Washington,

D.C.

WHO ,(1999), Guidelines for drinking water quality $.2^{\text {nd }}$ ed. 2.p:940- 949

World Health Organisation (WHO) (1985), Guidelines for Drinking Water Quality (II), Health Criteria and Supporting Information, WHO, Geneva, Switzerland 